Tobias Lüdtke, Dominik Weber, Alexander Schmidt, Alexander Müller, Christoph Reimann, Nils Becker, Thomas Bredow, Richard Dronskowski, Thorsten Ressler and Martin Lerch*

\title{
Synthesis and characterization of metastable transition metal oxides and oxide nitrides
}

DOI 10.1515/zkri-2016-1961

Received May 24, 2016; accepted June 25, 2016; published online July 21, 2016

\begin{abstract}
New routes to vanadium sesquioxide and tantalum oxide nitride ( $\gamma$ - and $\delta$-phase) are presented. Phase pure $\mathrm{V}_{2} \mathrm{O}_{3}$ with bixbyite-type structure, a metastable polymorph, was obtained from vanadium fluoride hydrates at $\sim 750 \mathrm{~K}$. It crystallizes in the cubic crystal system in space group $I a \overline{3}$ with lattice parameter $a=939.30(5) \mathrm{pm}$. The catalytical properties of the corresponding oxide nitride phases and their oxidation and reduction solid-state kinetics were investigated. The preparation of $\gamma$-TaON as a phase pure sample can be realized by ammonolysis of $\mathrm{X}$-ray amorphous tantalum oxide precursors at $1073 \mathrm{~K}$. This metastable tantalum oxide nitride crystallizes in the monoclinic $\mathrm{VO}_{2}(\mathrm{~B})$-type structure in space group $\mathrm{C} 2 / \mathrm{m}$. The same precursors can be used to synthesize the $\delta$-modification with an anatase-type structure at $1023 \mathrm{~K}$. It crystallizes in the tetragonal crystal system in space group I4/ /amd. A maximum yield of $82 \mathrm{~m} \%$ could be obtained. The fundamental band gaps of the synthesized and of other metastable TaON polymorphs were calculated from first principles using the GW method. The present results are compared to experimental data and to previous calculations at hybrid DFT level.
\end{abstract}

Keywords: metastable compounds; solid state chemistry.

\footnotetext{
*Corresponding author: Martin Lerch, Institut für Chemie, Technische Universität Berlin, Straße des 17. Juni 135, D-10623 Berlin, Germany, E-mail: martin.lerch@tu-berlin.de Tobias Lüdtke, Dominik Weber, Alexander Schmidt, Alexander Müller and Thorsten Ressler: Institut für Chemie, Technische Universität Berlin, Straße des 17. Juni 135, D-10623 Berlin, Germany

Christoph Reimann and Thomas Bredow: Mulliken Center for Theoretical Chemistry, Institut für Physikalische und Theoretische Chemie, University of Bonn, Beringstraße 4, D-53115 Bonn, Germany Nils Becker and Richard Dronskowski: Chair of Solid-State and Quantum Chemistry, Institute of Inorganic Chemistry, RWTH Aachen University, Landoltweg 1, D-52056 Aachen, Germany
}

\section{Introduction}

The physical properties of solids strongly depend on the arrangement of the atoms. For a deeper understanding of the correlations between crystal structure and physical properties investigations using simple compounds such as binary oxides or ternary oxide nitrides are most promising. In particular the syntheses of metastable polymorphs of such compounds pave the way to deeper insights into these nexuses. In the frame of the 'priority program' SPP 1415, funded by the German Science Foundation (DFG), synthesis routes to novel polymorphs of vanadium sesquioxide and tantalum oxide nitride were developed, backed by quantum-chemical calculations. In most cases it is very difficult to obtain phase pure materials important for an unambiguous interpretation of the data from the properties measurements. During the last years we published on synthesis and characterization of four new metastable phases: bixbyite-type $\mathrm{V}_{2} \mathrm{O}_{3}$ [1], anosovite-type $\mathrm{V}_{3} \mathrm{O}_{5}$ [2], $\mathrm{VO}_{2}$ (B)-type TaON [3], and anatase-type TaON [4]. Unfortunately, only anosovite-type $\mathrm{V}_{3} \mathrm{O}_{5}$ can be synthesized as single phase [2]. All other samples contained large amounts of side phases leading to severe problems concerning the investigation of physical properties. However, the crystal structures could be determined, also in combination with quantum-chemical methods [1-4]. Recently, we optimized the preparation techniques and in this contribution we present simple routes to phase pure bixbyitetype $\mathrm{V}_{2} \mathrm{O}_{3}$ and $\mathrm{VO}_{2}(\mathrm{~B})$-type $\mathrm{TaON}(\gamma$-TaON) [5]. The phase purity of anatase-type TaON ( $\delta$-TaON) is now increased from $42 \mathrm{wt} \%$ to $82 \mathrm{wt} \%$. Moreover, structure-property relationships were studied with respect to selective oxidation of light alkenes. Mixed oxide catalysts containing, for instance, vanadium or molybdenum, are active heterogeneous oxidation catalysts. Bixbyite-type oxide nitrides and corundum-type $\mathrm{V}_{2} \mathrm{O}_{3}$ were used as model catalysts for selective oxidation of propene. Therefore, oxidation of the materials was studied time-resolved under oxidation reaction conditions. Solid-state kinetics were evaluated by model-dependent and model-independent methods and the results correlated to structural and compositional properties. 
Transition metal oxides and oxide nitrides are considered as interesting materials for photocatalyis. The photocatalytic activity of the solid compounds is to a large extent determined by their fundamental and optical band gaps. Their experimental determination is not in all cases possible, in particular if the synthesized materials are not phase-pure. In this case theoretical calculations of band gaps have proven to be an indispensable tool to analyse the electronic structure of solid compounds. Furthermore, quantum-chemical methods allow predictions of structural, thermodynamic and electronic properties for metastable phases that have not yet been synthesized. In previous studies $[4,6,7]$ we have calculated fundamental band gaps of TaON polymorphs with hybrid functionals in order to account for the self-interaction error of standard density functional theory (DFT) using the semilocal generalized gradient approximation (GGA). The advantages and limitations of hybrid functionals for the study of the electronic properties of solid catalysts have been discussed recently [8]. In principle they are semi-empirical methods because the amount of Hartree-Fock exchange that is used in the exchange functional is not strictly determined from first principles. Additionally, the interpretation of KohnSham single-particle energies as ionization potentials and electron affinities has been questioned [9]. A nonempirical and physically correct description of fundamental band gaps is provided by the GW methodology which combines a Green function approach with a screened Coulomb potential $(\mathrm{W})$ to calculate the quasi-particle energies. Polarization effects in the environment of holes and electrons are taken into account. It has been shown that the GW method provides an accurate description of band gaps for a large variety of solids [10]. Several approximations of GW theory exist, e.g. non-self-consistent G0W0, GWO, or self-consistent GW. In the present study we apply the plasmon-pole approximation to GW as implemented in the GPAW program [11-13] to calculate the fundamental band gaps of those $\mathrm{TaON}$ polymorphs that have been studied here and in our previous works.

\section{Results and discussion}

\section{Bixbyite-type $\mathrm{V}_{2} \mathrm{O}_{3}$}

Vanadium oxide-based ceramics are used versatile. Possible application areas are, for example, catalysis [14, 15], chemical sensors [16], batteries [17], and optical and electric devices [18]. At ambient conditions, vanadium sesquioxide usually crystallizes in the rhombohedral corundum-type structure [19]. At $170 \mathrm{~K}$, it shows a so called Mott-Hubbard transition [20, 21] to the monoclinic M1 phase, which is antiferromagnetically ordered and an electric insulator [22-25].

In a previous publication we presented the synthesis of bixbyite-type $\mathrm{V}_{2} \mathrm{O}_{3}$ with a maximum yield of about 82 wt $\%$ with corundum-type $\mathrm{V}_{2} \mathrm{O}_{3}$ as side phase [1]. In addition, the electronic structure and thermodynamics have already been discussed [26]. Later on, phase pure nanocrystals with a diameter of 5-30 nm were successfully synthesized by Bergerud et al. [27]. Calculations predict Sc-, Y-, and especially Mg-doped bixbyite-type $\mathrm{V}_{2} \mathrm{O}_{3}$ to be promising $p$-type semiconductors [28]. With the adjusted synthesis conditions mentioned below we were able to isolate a phase pure sample as a grayish-black powder [5]: $\mathrm{V}_{2} \mathrm{~F}_{6} \cdot 4 \mathrm{H}_{2} \mathrm{O}$ and $\mathrm{V}_{2} \mathrm{~F}_{6} \cdot 6 \mathrm{H}_{2} \mathrm{O}$ [29] were used as precursors for an optimized synthesis. Those metal fluoride hydrates can be obtained by treating vanadium powder with hexafluorosilic acid and heating the mixture to $\sim 80^{\circ} \mathrm{C}$ until a dry powder is formed. The new vanadium oxide was prepared in a tube furnace with a corundum tube at temperatures between 748 and $758 \mathrm{~K}$ for $2 \mathrm{~h}$ with a heating rate of $300 \mathrm{~K} / \mathrm{h}$. A flow rate of $10 \mathrm{~L} / \mathrm{h}$ of the reaction gas (40-60 vol $\% \mathrm{H}_{2}$ in $\mathrm{Ar}$, gas stream piped through a water-filled washing flask) was used. The samples were cooled down in dry argon atmosphere.

The bixbyite-type polymorph of vanadium sesquioxide crystallizes in the cubic space group $I a \overline{3}$ with the lattice parameter $a=939.30(5) \mathrm{pm}$. The X-ray diffraction pattern with the results of the Rietveld refinement is shown in Figure 1. Details and refined parameters are presented in Tables 1 and 2.

Description of crystal structure: vanadium is coordinated by oxygen in two different ways. Both octahedraderived arrangements with the corresponding V-O-bond lengths are depicted in Figure 2. The perfect octahedron around V1 shows bond lengths of $200.8 \mathrm{pm}$, while for the (V2) $\mathrm{O}_{6}$-polyhedra bond lengths between 197.7 and $210.4 \mathrm{pm}$ (average $203.3 \mathrm{pm}$ ) are observed. All these values are in good agreement with the ionic radii of vanadium and oxygen [30].

The ideal bixbyite-type structure can be described as a $2 \times 2 \times 2$ superstructure of the fluorite-type by removing $1 / 4$ of the anions. This new unit cell has doubled cell parameters and ordered anion vacancies. One of the remarkable characteristics of this structure type is the possible partially occupation of these vacancies by additional anions leading to compositions with an oxygen excess: $\mathrm{A}_{2} \mathrm{X}_{3+x^{*}}$. This is described for the sesquinitride of uranium $\mathrm{U}_{2} \mathrm{~N}_{3}$ $[31,32]$ and the corresponding oxide nitrides of zirconium [33] and vanadium [34]. The oxygen content of vanadium 


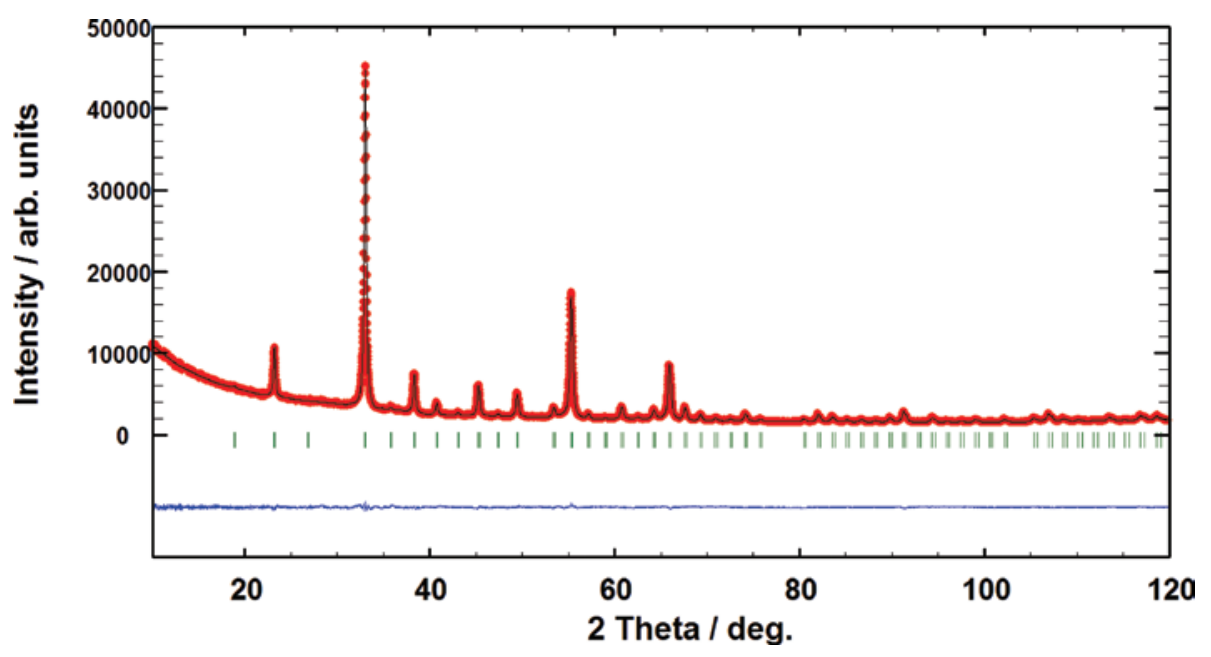

Fig. 1: X-ray powder diffraction pattern ( $\mathrm{Cu} \mathrm{K}$ radiation) of bixbyite-type $\mathrm{V}_{2} \mathrm{O}_{3}$ with results of the Rietveld refinement. The vertical bars indicate the positions of the Bragg reflections.

Tab. 1: Results of the Rietveld refinement for bixbyite-type $\mathrm{V}_{2} \mathrm{O}_{3}$.

\begin{tabular}{ll}
\hline & $\mathbf{V}_{2} \mathbf{O}_{3}$ \\
\hline Structure type & bixbyite \\
Space group & $I a \overline{3}$ \\
Crystal system & cubic \\
Lattice parameters & $a=939.30(5) \mathrm{pm}$ \\
Unit cell volume & $V=828.72(7) \cdot 10^{6} \mathrm{pm}^{3}$ \\
Formula units & $Z=16$ \\
Calculated density & $\rho=4.805 \mathrm{~g} / \mathrm{cm}^{3}$ \\
Diffractometer & $\mathrm{PANalytical} \mathrm{X'Pert} \mathrm{MPD} \mathrm{Pro}$ \\
$2 \theta$ range & $5-120^{\circ}$ \\
Wavelength & $\mathrm{CuK} \mathrm{K}_{\alpha 1}: \lambda_{1}=154.051 \mathrm{pm}$ \\
& $\mathrm{CuK} \mathrm{K}_{\alpha 2}: 154.433 \mathrm{pm}$ \\
& $\mathrm{I}\left(\lambda_{2}\right) / \mathrm{I}\left(\lambda_{1}\right)=0.497$ \\
Profile points & 8845 \\
Refined parameters & 47 \\
$R_{\text {wp }}$ & 0.022 \\
$R_{\text {exp }}$ & 0.019 \\
$R_{\text {Bragg }}$ & 0.038 \\
$S$ & 1.15 \\
\hline
\end{tabular}

Tab. 2: Refined atomic parameters of bixbyite-type $\mathrm{V}_{2} \mathrm{O}_{3}$.

\begin{tabular}{llrrrr}
\hline Atom & Wyckoff & $\mathbf{x}$ & $\mathbf{y}$ & $\mathbf{z}$ & $\boldsymbol{B}_{\text {iso }} / \mathbf{1 0}^{4} \mathbf{~ p m}^{2}$ \\
\hline V1 & $8 a$ & 0 & 0 & 0 & $0.70(4)$ \\
V2 & $24 d$ & $0.28174(5)$ & 0 & $1 / 4$ & $0.77(3)$ \\
01 & $48 e$ & $0.1422(2)$ & $0.1281(2)$ & $-0.0954(2)$ & $0.77(3)$ \\
\hline
\end{tabular}

sesquioxides prepared by our new route was determined by hot gas extraction: $31.8-32.2 \mathrm{wt} \%$. Taking into account the error range (the accuracy is $\sim 2 \%$ of the $\mathrm{N} / \mathrm{O}$ contents present), these results are in good agreement with the ideal $\mathrm{V}_{2} \mathrm{O}_{3}$ composition for the sesquioxide (32.0 wt \% oxygen). Calculations on DFT level show that a formation
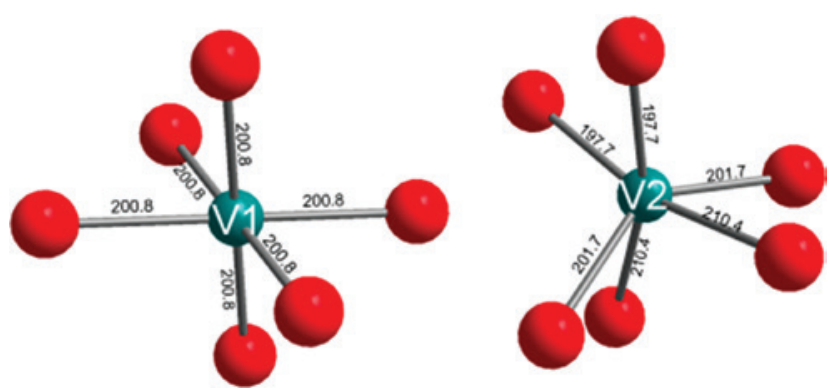

Fig. 2: Coordination polyhedra of bixbyite-type $\mathrm{V}_{2} \mathrm{O}_{3}$. Bond lengths are presented in $\mathrm{pm}$.

of nonstoichiometric $\mathrm{V}_{2} \mathrm{O}_{3+x}$ phases by incorporation of excess oxygen is possible, depending on the oxygen activity during synthesis [35]. No hydrogen was detectable using combustion analysis. The absence of remaining precursor-fluoride was proved by EDX, WDX, and XFA. The new vanadium oxide is metastable (about $9 \mathrm{~kJ} / \mathrm{mol}$ less stable than the thermodynamically stable polymorph [1] and largely independent from the quantum-mechanical method) and transforms to corundum-type $\mathrm{V}_{2} \mathrm{O}_{3}$ at $\sim 823 \mathrm{~K}$ in argon atmosphere. An oxidation to $\mathrm{V}_{2} \mathrm{O}_{5}$ can be observed in air at $\sim 523 \mathrm{~K}$. At ambient conditions it oxidizes to $\mathrm{VO}_{2}$ in a period of 3 weeks.

Additionally, the synthesis of phase pure bulk material allows the investigation of the physical properties. Neutron diffraction experiments and the determination of magnetic properties have already been carried out [5].

Moreover, vanadium oxides are active and selective heterogeneous catalysts for partial oxidation of light alkanes and alkenes with gas-phase oxygen. Structurefunction correlations of bixbyite-type vanadium sesquioxide were studied for the heterogeneous selective oxidation 
of propene to acrolein. Here, bixbyite-type vanadium oxide nitrides were employed permitting an additional variation of electronic and structural properties as a function of nitrogen content. Preparation conditions and materials characterization are described in Ref. [34].

Corresponding vanadium oxide nitrides and corundum-type $\mathrm{V}_{2} \mathrm{O}_{3}$ oxidized under catalytic conditions to rutile-type $\mathrm{VO}_{2}$. Hence, oxidation behavior under catalytic conditions was investigated by in situ X-ray absorption spectroscopy (XAS) measurements at the V K edge. Evolution of $\mathrm{V}$ K edge XANES spectra of corundum-type $\mathrm{V}_{2} \mathrm{O}_{3}$ during isothermal treatment under catalytic conditions at $633 \mathrm{~K}$ is shown in Figure 3. The distinct XANES features of the various vanadium oxides permitted a quantitative analysis of the evolution of the phase composition during oxidation. Thus, the amount of $\mathrm{VO}_{2}(\mathrm{R})$ was extracted from a linear combination analysis (LCA) using reference spectra of corundum-type $\mathrm{V}_{2} \mathrm{O}_{3}$ and $\mathrm{VO}_{2}(\mathrm{~B})$. Principal component analysis indicated these two references spectra to be sufficient to describe the experimental spectra excluding the formation of significant amounts of crystalline or amorphous intermediates or by-products. This makes the studied oxide nitrides and oxides suitable model systems for investigating solid-state kinetics under reaction conditions.

In situ X-ray diffraction experiments under catalytic condition ( 5 vol\% propene, 5 vol $\%$ oxygen in helium) were performed for oxide nitrides with the composition $\mathrm{V}_{2} \mathrm{O}_{3.03} \mathrm{~N}_{0.02}, \mathrm{~V}_{2} \mathrm{O}_{3.08} \mathrm{~N}_{0.06}$ and $\mathrm{V}_{2} \mathrm{O}_{3.04} \mathrm{~N}_{0.07}$ and for corundumtype $\mathrm{V}_{2} \mathrm{O}_{3}$. Figure 4 shows the oxidation degree $\alpha$ traces for the isothermal treatment of oxide nitride with the composition $\mathrm{V}_{2} \mathrm{O}_{3.08} \mathrm{~N}_{0.06}$ under catalytic conditions (5 vol\% propene, 5 vol\% oxygen in helium) measured by isothermal in situ X-ray diffraction. Isothermal measurements were performed at temperatures of $623 \mathrm{~K}, 633 \mathrm{~K}, 643 \mathrm{~K}$, and $653 \mathrm{~K}$. Similar to the oxidation degree $\alpha$ traces of

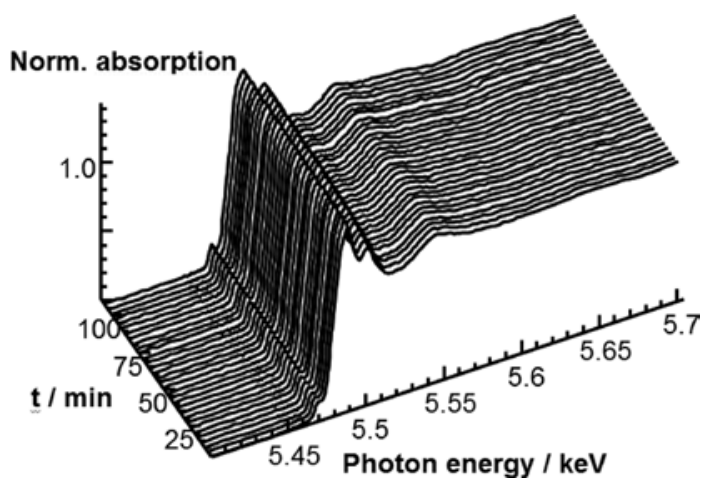

Fig. 3: In situ V K edge XANES spectra measured during isothermal treatment of corundum-type $\mathrm{V}_{2} \mathrm{O}_{3}$ under catalytic conditions ( 5 vol\% propene, 5 vol\% oxygen in helium) at $633 \mathrm{~K}$.

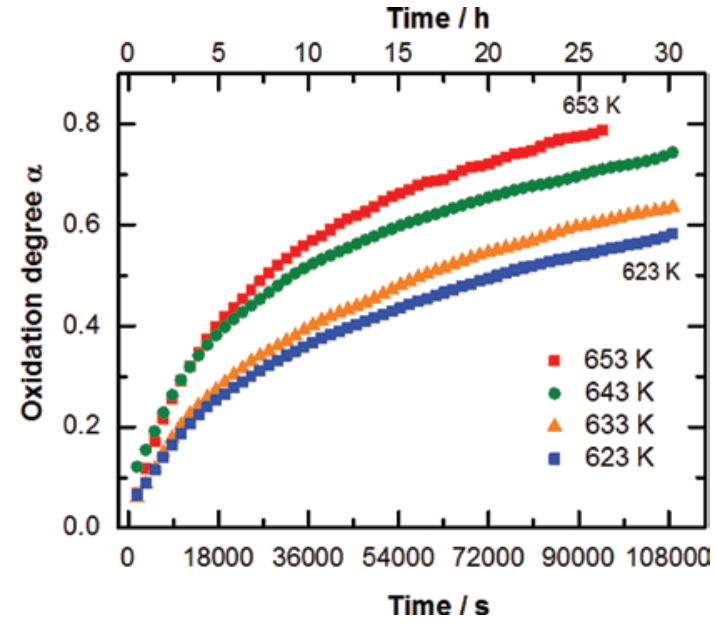

Fig. 4: Evolution of oxidation degree during isothermal oxidation as a function of time during isothermal oxidation of oxide nitride with bixbyite structure with the composition $\mathrm{V}_{2} \mathrm{O}_{3.08} \mathrm{~N}_{0.06}$ in 5 vol\% propene, 5 vol\% oxygen in helium at $623 \mathrm{~K}, 633 \mathrm{~K}, 643 \mathrm{~K}$, and $653 \mathrm{~K}$. Traces were extracted from in situ $\mathrm{X}$-ray diffraction measurements.

$\mathrm{V}_{2} \mathrm{O}_{3.03} \mathrm{~N}_{0.02}$, the shape of the oxidation degree $\alpha$ traces of $\mathrm{V}_{2} \mathrm{O}_{3.08} \mathrm{~N}_{0.06}$ was characterized by an exponentially limited increase with reaction times. An induction period for the early stage of oxidation was not observed.

Oxidation degree $\alpha$ traces were evaluated by several solid-state kinetic reaction models. The model-dependent analysis suggested that oxidation of $\mathrm{V}_{2} \mathrm{O}_{3.08} \mathrm{~N}_{0.06}$ to $\mathrm{VO}_{2}(\mathrm{R})$ under catalytic conditions ( $5 \mathrm{vol} \%$ propene, $5 \mathrm{vol} \%$ oxygen in helium) was governed by three-dimensional diffusion. Figure 5 shows the linearized oxidation degree $\alpha$ traces using the Jander [36] and Ginstling-Brounshtein [37]

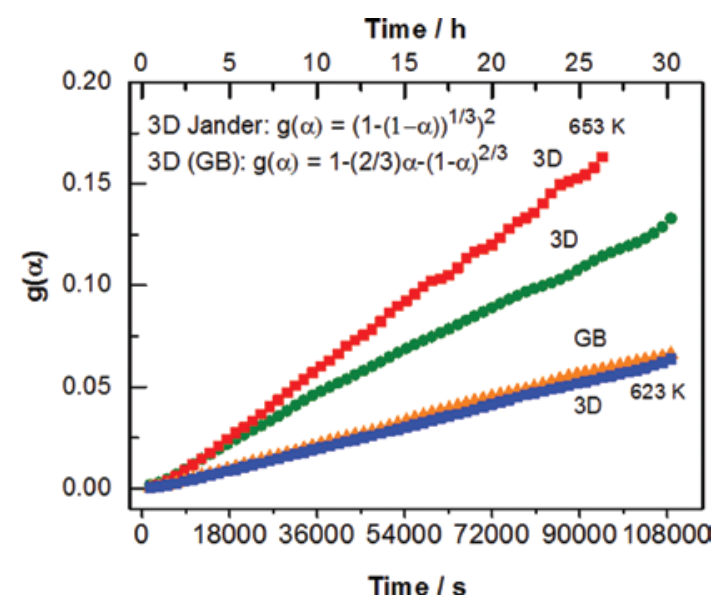

Fig. 5: Linearization of oxidation degree $\alpha$ traces for isothermal oxidation of $\mathrm{V}_{2} \mathrm{O}_{3.08} \mathrm{~N}_{0.06}$ with bixbyite to $\mathrm{VO}_{2}(\mathrm{R})$ using three-dimensional diffusion models (D3, Jander; D4, Ginstling-Brounshtein). Isothermal measurements were performed under catalytic conditions ( 5 vol\% propene, 5 vol\% oxygen in helium) at $623 \mathrm{~K}, 633 \mathrm{~K}, 643 \mathrm{~K}$ and, $653 \mathrm{~K}$. 
solid-state reaction models that assume three-dimensional diffusion as rate-determining step. Apparently, the $\alpha$ traces can be sufficiently described by a single rate-determining step. Schematically, three-dimensional Jander and Ginstling-Brounshtein diffusion solid-state reaction models assume a spherical particle consisting of a $\mathrm{V}_{2} \mathrm{O}_{3}$ core and a $\mathrm{VO}_{2}(\mathrm{R})$ shell. With ongoing oxidation, the shell is growing until the initial reactant in the core is consumed. The reaction rate is limited by diffusion of $\mathrm{O}^{2-}$ species through the product shell to the core-shell interface and conduction of electrons from the interface to the particle surface. Similar results were obtained from a model-dependent kinetic analysis of data measured during isothermal oxidation of $\mathrm{V}_{2} \mathrm{O}_{3.08} \mathrm{~N}_{0.02}$ and corundum-type $\mathrm{V}_{2} \mathrm{O}_{3}$. Hence, various amounts of nitrogen did not induce a change in the rate determining step $g(\alpha)$ for the oxidation reaction. Apparent activation energies for the rate-determining step in the oxidation of $\mathrm{V}_{2} \mathrm{O}_{3.08} \mathrm{~N}_{0.02}, \mathrm{~V}_{2} \mathrm{O}_{3.08} \mathrm{~N}_{0.06}$, and corundum-type $\mathrm{V}_{2} \mathrm{O}_{3}$ amounted to $150 \mathrm{~kJ} / \mathrm{mol}, 122 \mathrm{~kJ} / \mathrm{mol}$, and $87 \mathrm{~kJ} / \mathrm{mol}$, respectively.

Model-independent (isoconversional) analysis of solid-state kinetic data measured for oxidation of oxide nitrides with bixbyite structure and corundum-type $\mathrm{V}_{2} \mathrm{O}_{3}$ yielded the evolution of the apparent activation energy with oxidation degree $\alpha$ (Figure 6). The obtained traces showed an increase of the apparent activation energy $E_{a \alpha}$ at $\alpha$ values below 0.4 . The increase of the apparent activation energy $E_{a \alpha}$ for the oxidation of $\mathrm{V}_{2} \mathrm{O}_{3.08} \mathrm{~N}_{0.06}$ shifted to lower oxidation degree $\alpha$ values compared to $\mathrm{V}_{2} \mathrm{O}_{3.03} \mathrm{~N}_{0.02}$ and corundum-type $\mathrm{V}_{2} \mathrm{O}_{3}$ (Figure 6). In contrast to $\mathrm{V}_{2} \mathrm{O}_{3.03} \mathrm{~N}_{0.02}$ and corundum-type $\mathrm{V}_{2} \mathrm{O}_{3}$, an initial decrease of the apparent activation energy $E_{a \alpha}$ was not observed for $\mathrm{V}_{2} \mathrm{O}_{3.08} \mathrm{~N}_{0.06}$. The maximum value for the apparent activation energies

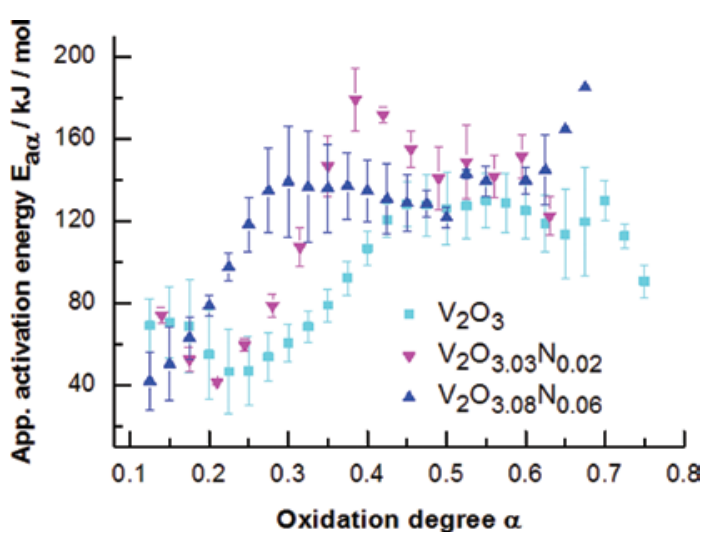

Fig. 6: Evolution of apparent ctivation energies $E_{a \alpha}$ of the rate determining step $g(\alpha)$ for the oxidation of oxide nitrides $V_{2} O_{3.03} \mathrm{~N}_{0.02}$, $\mathrm{V}_{2} \mathrm{O}_{3.08} \mathrm{~N}_{0.06}$, and corundum-type $\mathrm{V}_{2} \mathrm{O}_{3}$ under catalytic conditions ( 5 vol\% propene, 5 vol\% oxygen in helium).
$E_{a \alpha}$ for both, oxide nitrides and corundum-type $\mathrm{V}_{2} \mathrm{O}_{3}$, were similar (Figure 6). For the oxide nitrides, the apparent activation energy at higher $\alpha$ values agreed well with the results of the model-dependent analysis. Conversely, the lower apparent activation energy obtained for corundumtype $\mathrm{V}_{2} \mathrm{O}_{3}$ appeared to correspond to an average over the entire $\alpha$ range.

Mechanistically, the increasing apparent activation energy $E_{a \alpha}$ may correspond to the generation of $\mathrm{VO}_{2}(\mathrm{R})$ nuclei in the early stage of oxidation under catalytic conditions. This was followed by a transition into a diffusion-controlled stage according to the three-dimensional diffusion models identified by the model-dependent analysis. With increasing amount of nitrogen in the samples, the change in regimes was shifted to lower $\alpha$ values (Figure 6). Apparently, nucleation, formation of a $\mathrm{VO}_{2}(\mathrm{R})$ product layer, and transition into a diffusion-controlled stage were facilitated by incorporation of nitrogen. With respect to catalytic properties and according to the mechanism of selective oxidation of light hydrocarbons on metal oxide catalysts, oxygen vacancies were generated at the surface of the catalysts and subsequently diffused into the bulk during the catalytic cycle. Formation of $\mathrm{VO}_{2}(\mathrm{R})$ during oxidation depended on the density of oxygen vacancies in the bulk of oxide nitrides and corundum-type $\mathrm{V}_{2} \mathrm{O}_{3}$. For oxide nitrides the refinement of V K edge $\mathrm{FT}\left(\chi(k) \cdot k^{3}\right)$ revealed an increasing V-O disorder parameter $\sigma^{2}$ with an increasing amount of nitrogen. Because $\sigma^{2}$ scales with the density of oxygen vacancies in the solid, this indicated an increased $\mathrm{O}^{2-}$ mobility under catalytic conditions. The latter in turn resulted in facilitated oxidation and the observed shift of $E_{a \alpha}$ to lower $\alpha$ values for oxidation of $\mathrm{V}_{2} \mathrm{O}_{3.08} \mathrm{~N}_{0.06}$ compared to $\mathrm{V}_{2} \mathrm{O}_{3.03} \mathrm{~N}_{0.02}$.

\section{$\mathrm{VO}_{2}$ (B)-type $\gamma$-TaON}

More than 50 years ago, Brauer and Weidlein reported the first tantalum(V) oxide nitride: yellow $\beta$-TaON. Crystallizing in the well-known monoclinic baddeleyit-type structure, it is the most stable phase in this system [38]. Reports of a nearly simultaneous discovered $\alpha$-polymorph $[39,40]$ have been rebutted by quantum-chemical calculations [41]. A high-pressure modification with cotunnite-type structure and nine-fold coordinated cations was predicted independently by two different groups $[42,43]$ and synthesized by Woodhead et al. [44]. $\gamma$-TaON is the first metastable polymorph and was described almost a decade ago by Schilling et al. [3]. The main side phase in our previous publication was $\beta-\mathrm{Ta}_{2} \mathrm{O}_{5}$ and the maximum yield was determined to 85 wt \% [3]. Single phase material with 
hollow urchin-like nanostructures have been analyzed in terms of photocatalytic activity by Wang et al. [45]. Another preparation method via a modified urea route has also been reported by Gao et al. [46]. Based on the work of Schilling et al. [3], optimized synthesis conditions allow us to obtain a phase pure sample of orange colored $\gamma$-TaON via a classical ammonolysis reaction [5]. Amorphous tantalum oxide precursors were prepared via a modified Pechini route [47]. Tantalum chloride (99.999\%, Sigma-Aldrich) was solved in an ethanol-citric acid solution. Citric acid was used in a molar excess of 12 times the $\mathrm{TaCl}_{5^{\circ}}$. Ethylene glycol in a molar excess of 17 times the tantalum chloride was added for the gelling process. The polymerization was finalized by heating the mixture up to $473 \mathrm{~K}$. The material was calcined at $623-773 \mathrm{~K}$ until a colorless X-ray amorphous powder was formed. $\gamma$-TaON was synthesized by ammonolysis of these amorphous precursors in a $\mathrm{SiO}_{2}$ tube at $1073 \mathrm{~K}$ for $3 \mathrm{~h}$ and a heat rate of $400 \mathrm{~K} / \mathrm{h}$. The volume flow rate of $\mathrm{NH}_{3}$ was $7 \mathrm{~L} / \mathrm{h}$ and of $\mathrm{O}_{2}$ $0.03 \mathrm{~L} / \mathrm{h}$.

It should be mentioned that possible applications of tantalum oxide nitrides are fast ion conductors [48], the usage as nontoxic color pigments [49] or as anodematerials for photocatalytical water splitting under sunlight [50]. Our optical measurements on the phase pure samples gave an indirect optical band gap of $2.03 \mathrm{eV}$ and a direct band gap of $2.59 \mathrm{eV}$, respectively [51]. Thus also this material might be a candidate for photocatalytical water splitting. It crystallizes in the monoclinic $\mathrm{VO}_{2}(\mathrm{~B})$ type structure in space group $\mathrm{C} / \mathrm{m}$. The X-ray powder diffraction pattern with results of the Rietveld refinement is shown in Figure 7. Tables 3 and 4 summarize the refined parameters.
The density of this metastable polymorph $\left(8.756 \mathrm{~g} / \mathrm{cm}^{3}\right)$ is smaller than the density of baddeleyite-type $\beta$-TaON $\left(11.02 \mathrm{~g} / \mathrm{cm}^{3}\right)$ [52]. According to the Ostwald-Volmer rule, metastable polymorphs are usually characterized by lower densities and transform to more stable modifications at increased temperatures [53]. A discrepancy of this rule will be discussed later.

The crystal structure and the Ta coordination polyhedra are depicted in Figures 8 and 9. Oxygen and nitrogen are occupying four different anion-sites, marked as $\mathrm{X} 1$ to $\mathrm{X} 4$. The corresponding coordination numbers are increasing from 2 for $\mathrm{X} 1$ to 3 for $\mathrm{X} 2$ and $\mathrm{X} 3$ up to 4 for the $\mathrm{X} 4$ position. Investigations regarding the precise anion ordering are impossible due to the fact that $\mathrm{N}$ and $\mathrm{O}$ are not distinguishable in X-ray diffraction experiments. DFT calculations using a large variety of methods not only determined the most probable of the six possible arrangements (oxygen occupying the $\mathrm{X} 1$ and $\mathrm{X} 2$ positions, nitrogen the other two anion sites (X3 and X4) $[3,6])$ but also provided theoretical standard deviations for all structural parameters.

Besides the poor quality of the fit, the presented bond lengths in Figure 5 are a further hint for insufficient structural parameters. Ta1 is coordinated by anions with an average distance of $211.2 \mathrm{pm}$, which is considerably larger than the calculated value based on quantum-chemical calculations (207.4 pm) [6]. A better agreement can be found for the Ta2 polyhedron: the average bond length (203.0 pm) is slightly shorter than the calculated length (203.4 pm). Especially the disproportionately large Ta1-N2 bond length of $260.5 \mathrm{pm}$ and the short Ta2-N1 length of $187.3 \mathrm{pm}$ are not reasonable in respect to the corresponding ionic radii of tantalum and nitrogen (sum of radii: $210.0 \mathrm{pm}$ ) [30, 54].

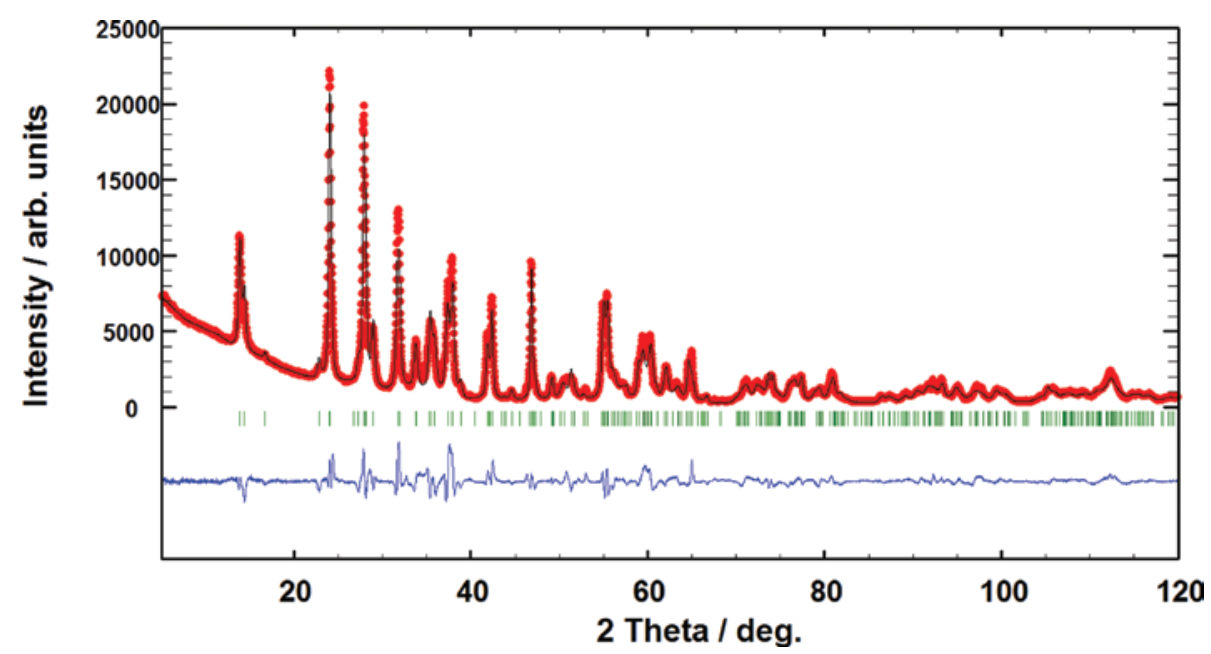

Fig. 7: X-ray powder diffraction pattern ( $\mathrm{CuK}_{\alpha 1}$ radiation) of $\gamma-\mathrm{TaON}$ with results of the Rietveld refinement. The vertical bars indicate the positions of the Bragg reflections. 
Tab. 3: Results of the Rietveld refinement for $\gamma$-TaON.

\begin{tabular}{ll}
\hline & $\boldsymbol{\gamma}$-TaON \\
\hline Structure type & $\mathrm{VO}_{2}(\mathrm{~B})$ \\
Space group & $\mathrm{C} 2 / m$ \\
Crystal system & Monoclinic \\
Lattice parameters & $a=1293.1(2) \mathrm{pm}$ \\
& $b=387.37(5) \mathrm{pm}$ \\
& $\mathrm{C}=669.80(10) \mathrm{pm}$ \\
Unit cell volume & $\beta=107.442(6)^{\circ}$ \\
Formula units & $V=320.08(8) \cdot 10^{6} \mathrm{pm}^{3}$ \\
Calculated density & $Z=8$ \\
Diffractometer & $\rho=8.756 \mathrm{~g} / \mathrm{cm}^{3}$ \\
$2 \theta$ range & $\mathrm{Siemens} \mathrm{D5000}$ \\
Wavelength & $5-120^{\circ}$ \\
Profile points & $\mathrm{CuK}: \lambda=154.051 \mathrm{pm}$ \\
Refined parameters & 6144 \\
$R_{\text {wp }}$ & 66 \\
$R_{\text {exp }}$ & 0.111 \\
$R_{\text {Bragg }}$ & 0.022 \\
\hline
\end{tabular}

Tab. 4: Refined atomic parameters of $\gamma$-TaON.

\begin{tabular}{llrrrr}
\hline Atom & Wyckoff & $\mathbf{x}$ & $\mathbf{y}$ & $\mathbf{z}$ & $\boldsymbol{B}_{\text {iso }} / \mathbf{1 0}^{4} \mathbf{p m}^{2}$ \\
\hline Ta1 & $4 i$ & $0.3075(2)$ & 0 & $0.2027(4)$ & $0.94(7)$ \\
Ta2 & $4 i$ & $0.6014(2)$ & 0 & $0.2052(4)$ & $1.08(7)$ \\
O1 (X1) & $4 i$ & $0.390(2)$ & 0 & $0.505(4)$ & $0.91^{\mathrm{a}}$ \\
O2 (X2) & $4 i$ & $0.142(2)$ & 0 & $0.173(3)$ & $0.91^{\mathrm{a}}$ \\
N1 (X3) & $4 i$ & $0.456(3)$ & 0 & $0.127(5)$ & $0.4(5)^{\mathrm{b}}$ \\
N2 (X4) & $4 i$ & $0.764(3)$ & 0 & $0.199(5)$ & $0.4(5)^{\mathrm{b}}$ \\
\hline
\end{tabular}

${ }^{\text {a }}$ Manually refined parameters.

${ }^{\mathrm{b}}$ Not refined independently.
As mentioned above, the difference plot, the residuals, and the goodness of fit $\mathrm{S}$ are indicating a not satisfying accordance between experimental data and theoretical structure model. A more detailed look at the powder diffraction diagram shows that the deviations mainly come from intensity problems together with reflection shifts. All this is probably caused by the presence of shear planes in the layer-like $\mathrm{VO}_{2}$ (B)-type crystal structure. There are no indications for severe anisotropic reflection broadening. These observations are already known from previous investigations regarding $\gamma$-TaON [3]. Furthermore, the determination of the anion positions is very difficult besides the heavy scattering Ta atoms. The Rietveld refinement provided always negative values for $B_{\text {iso }}$ for the anion positions. Consequently, the isotropic Debye-Waller factors for oxygen were altered manually until those factors for oxygen and nitrogen were positive and therefore reasonable under physical aspects. Interestingly, the same refinement problems can be observed for the single phase material with hollow urchin-like nanostructures [45] pointing to a general problem in the structural description of $\gamma-\mathrm{TaON}$.

Quantitative N/O analysis resulted in $8.1 \mathrm{wt} \%$ oxygen and 6.2 wt \% nitrogen, resulting in a composition of $\mathrm{TaO}_{1.07} \mathrm{~N}_{0.93}$. Respecting the experimental accuracy of $2 \%$ this is in an acceptable accordance with the expected ideal composition TaON. It should be mentioned that investigations regarding non-stoichiometric phases of $\beta$-TaON and $\mathrm{Ta}_{3} \mathrm{~N}_{5}$ have been published recently [55]. From these results a deviation from the ideal anion composition should not be completely ruled out. In situ temperature-dependent $\mathrm{X}$-ray diffraction experiments show a transformation to

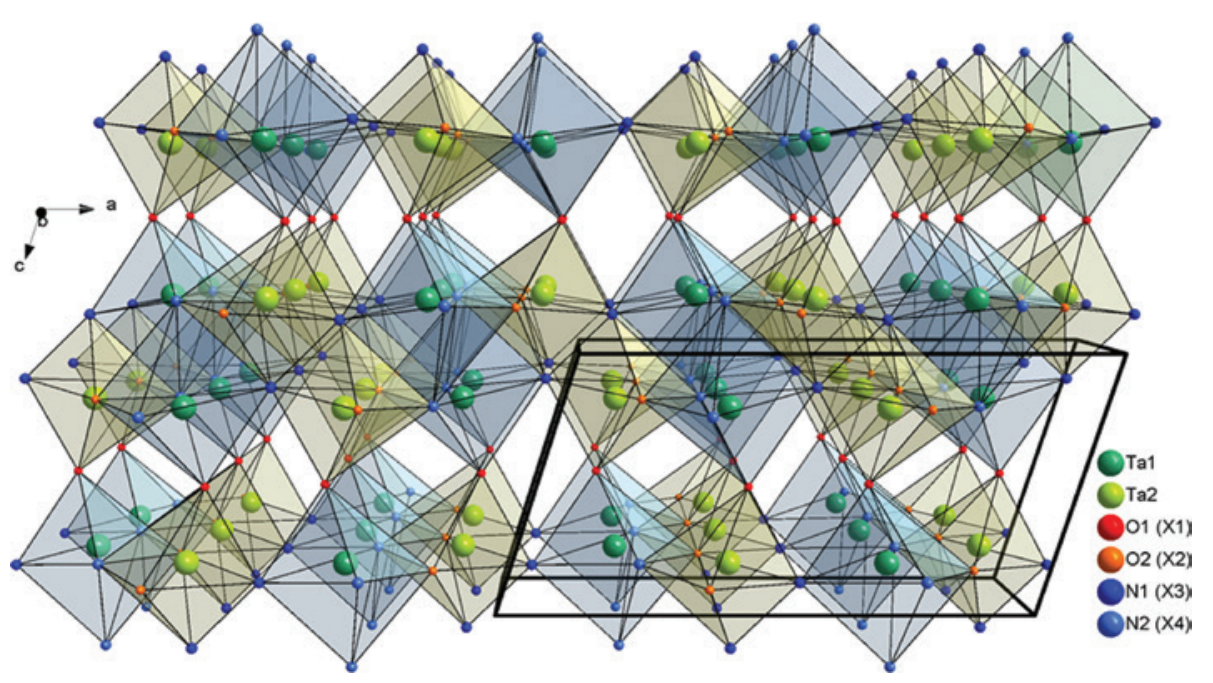

Fig. 8: Crystal structure with eight unit cells of $\gamma$-TaON. 


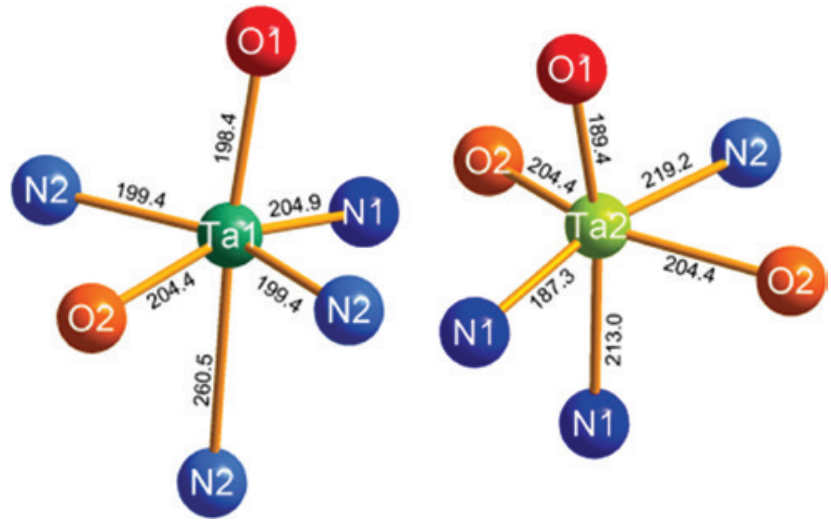

Fig. 9: Coordination polyhedra of $\gamma-\mathrm{TaON}$. Bond lengths are presented in $\mathrm{pm}$.

$\beta$-TaON in nitrogen atmosphere at $\sim 900{ }^{\circ} \mathrm{C}$. Calculations show that this metastable polymorph is $\sim 17 \mathrm{~kJ} / \mathrm{mol}$ less stable than $\beta$-TaON [3].

A comparison to our first publication on this phase could be misleading. The provided weighted residual $\left(R_{\mathrm{wp}}=0.089\right)$ [3] of the Rietveld refinement is better than the value in this new investigation $\left(R_{\mathrm{wp}}=0.111\right)$. The presence of $\mathrm{Ta}_{2} \mathrm{O}_{5}$ as a side phase, which can be better refined than the oxide nitride, has impact on the overall phase analysis. Besides the unsatisfying refinement results, the successful preparation of phase pure bulk material is the first step to solve most of the discussed problems. A more detailed analysis with the help of neutron diffraction measurements is strongly advised and an objective for future studies. Besides, the anion ordering has only been discussed theoretically [3], which can be analyzed with this method.

\section{Anatase-type $\delta$-TaON}

First discoveries of an anatase-type structure in tantalum oxide nitride phases have been made by incorporating small amounts of $\mathrm{Mg}^{2+}$ [56] or $\mathrm{Sc}^{3+}$ [57] ions. In fact, $\mathrm{Mg}_{0.05} \mathrm{Ta}_{0.95} \mathrm{O}_{1.15} \mathrm{~N}_{0.85}$ was the first example for this particular structure type without the element titanium. Relative stabilities for pure TaON in different crystal structures have been determined by quantum-chemical calculations, resulting in the following order of structure types with decreasing stability: baddeleyite $-\mathrm{VO}_{2}(\mathrm{~B})$ - anatase [7]. The latter has already been synthesized as thin film by Suzuki et al. $[58,59]$. The optical band gap has been determined to $2.37 \mathrm{eV}$. Analyses on bulk material has been published recently (indirect band gap: $1.73 \mathrm{eV}$, direct: $2.06 \mathrm{eV}$ ) [51]. It should be noted that those measurements have not been carried out on phase pure samples.

In our previous work we were able to synthesize a sample of anatase-type $\delta$-TaON with a maximum yield of 43 wt \% [4]. Structural refinements were performed on a sample ( $35 \mathrm{wt} \% \delta$-TaON) without $\gamma$-TaON as a side phase to avoid the above mentioned difficulties in the structure refinement. With our new synthesis conditions (ammonolysis of amorphous precursors mentioned above in an $\mathrm{SiO}_{2}$ tube at $1023 \mathrm{~K}$, reaction time of $0.75 \mathrm{~h}$, heat rate of $400 \mathrm{~K} / \mathrm{h}$, and flow rates of $12.50 \mathrm{~L} / \mathrm{h}$ ammonia and $0.03 \mathrm{~L} / \mathrm{h}$ oxygen) it was possible to increase the yield of the desired phase up to $82 \mathrm{wt} \%$, but it was unavoidable to get $\gamma$-TaON (6 wt \%) as a side phase in addition to the always present dark red $\mathrm{Ta}_{3} \mathrm{~N}_{5}(12 \mathrm{wt} \%)$. The latter has a significant influence on the red color of the product.

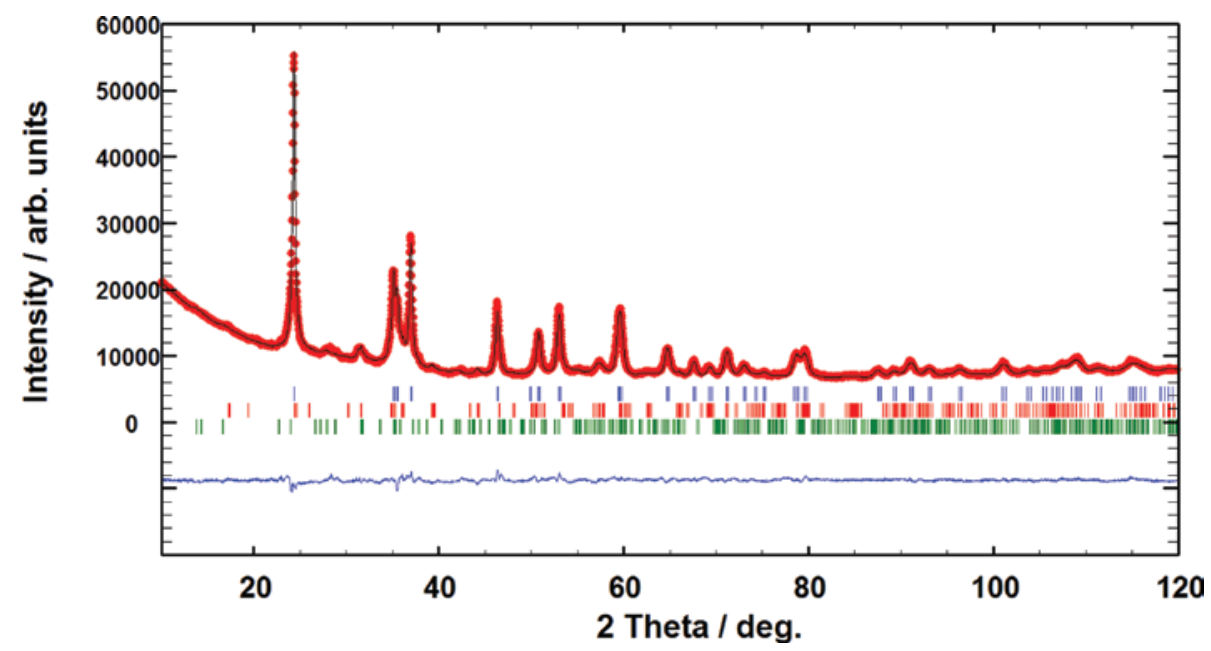

Fig. 10: X-ray powder diffraction pattern ( $\mathrm{Cu} \mathrm{K}_{\bar{\alpha}}$ radiation) of $\delta$-TaON with results of the Rietveld refinement. The vertical bars indicate the positions of the Bragg reflections (blue: $\delta$-TaON 82 wt \%, red: $\mathrm{Ta}_{3} \mathrm{~N}_{5} 12 \mathrm{wt} \%$, green: $\gamma$-TaON 6 wt \%). 
The powder diffraction pattern is shown in Figure 10. The Rietveld refinement was carried out using the tetragonal space group $\mathrm{I}_{1} / \mathrm{amd}$, which does not allow an ordered anion arrangement. This problem has already been discussed elsewhere multiple times [4, 7, 56, 60]. Refined parameters are listed in Tables 5 and 6.

The presence of two side phases with strongly overlapping reflections has a noticeable influence on the Rietveld refinement, which is indicated by a relatively high $R_{\text {Bragg }}$ value of 0.047 for the main phase. At an angular region of $2 \theta=\sim 24^{\circ}$, for example, the strongest reflections of both metastable $\mathrm{TaON}$ modifications and $\mathrm{Ta}_{3} \mathrm{~N}_{5}$ are located. Additionally, the difficulties regarding the refinement of the $\gamma$-phase mentioned above must also be taken under consideration. This was the main reason to choose a sample without this side phase in the previous publication [4]. The isotropic Debye-Waller-factors have been fixed to values from neutron diffraction experiments on $\mathrm{Mg}_{0.05} \mathrm{Ta}_{0.95} \mathrm{O}_{1.15} \mathrm{~N}_{0.85}[56]$.

In contrast to the Ostwald-Volmer rule [53], this metastable polymorph of tantalum oxide nitride has a

Tab. 5: Results of the Rietveld refinement for $\delta$-TaON.

\begin{tabular}{ll}
\hline & $\boldsymbol{\delta}$-TaON \\
\hline Structure type & Anatase \\
Space group & I4 $/$ amd \\
Crystal system & Tetragonal \\
Lattice parameters & $a=391.872(17) \mathrm{pm}$ \\
& $\mathrm{C}=1010.66(5) \mathrm{pm}$ \\
Unit cell volume & $V=155.201(13) \cdot 10^{6} \mathrm{pm}^{3}$ \\
Formula units & $Z=4$ \\
Calculated density & $\rho=9.028 \mathrm{~g} / \mathrm{cm}^{3}$ \\
Diffractometer & PANalytical X'Pert MPD Pro \\
$2 \theta$ range & $10-120^{\circ}$ \\
Wavelength & CuK $: \lambda_{1}=154.051 \mathrm{pm}$ \\
& CuK $\mathrm{K}_{\alpha 2}: \lambda_{2}=154.433 \mathrm{pm}$ \\
Profile points & $\mathrm{I}\left(\lambda_{2}\right) / \mathrm{I}\left(\lambda_{1}\right)=0.497$ \\
Refined parameters & 4224 \\
$R_{\text {wp }}$ & 36 \\
$R_{\text {exp }}$ & 0.022 \\
$R_{\text {Bragg }}$ & 0.010 \\
$S$ & 0.047 \\
\hline
\end{tabular}

Tab. 6: Refined atomic parameters for $\delta$-TaON.

\begin{tabular}{lllrrr}
\hline Atom & Wyckoff & $\mathbf{x}$ & $\mathbf{y}$ & $\mathbf{z}$ & $\boldsymbol{B}_{\text {iso }} / \mathbf{1 0}^{4} \mathbf{p m}^{2}$ \\
\hline $\mathrm{Ta}$ & $4 b$ & 0 & $1 / 4$ & 0.375 & $1.3^{\mathrm{a}}$ \\
$\mathrm{N} / \mathrm{O}^{\mathrm{b}}$ & $8 e$ & 0 & $1 / 4$ & $0.5875(6)$ & $1.4^{\mathrm{a}}$ \\
\hline
\end{tabular}

${ }^{\text {a }}$ Fixed to the results from neutron diffraction, Ref. [56].

${ }^{b}$ Not refined independently. slightly larger density $\left(\rho=9.029 \mathrm{~g} / \mathrm{cm}^{3}\right)$ than the more stable $\gamma$-TaON $\left(\rho=8.756 \mathrm{~g} / \mathrm{cm}^{3}\right)$ with its huge tunnels. Anatase-type structures are also characterized by tunnels along the $\mathrm{a}$ - and $\mathrm{b}$-axis (Figure 11), but the cavities are not as distinctive as in the $\mathrm{VO}_{2}(\mathrm{~B})$-type structure. Just one type of coordination polyhedron can be found in the anatase-type structure (Figure 11). Tantalum marks the center of an elongated and slightly distorted octahedron with anions on its edges. The four nearest anions with a distance of $199.6 \mathrm{pm}$ are tilted out of the ideal equatorial plane by an angle of $\pm 11^{\circ}$, whereas the bonds in the axial direction are noticeably larger $(214.8 \mathrm{pm})$. In comparison to $\mathrm{Mg}_{0.05} \mathrm{Ta}_{0.95} \mathrm{O}_{1.15} \mathrm{~N}_{0.85}$ the bond lengths are in a good agreement with experimental (200.3-211.3 pm) [56] and calculated (200.0-214.0 pm) [60] values of the Mg-containing compound. Such deformed octahedra are also well known from anatase-type $\mathrm{TiO}_{2}$ (193.4-197.9 pm) [61].

A phase transition to $\beta$-TaON can be observed at temperatures between 1073 and $1123 \mathrm{~K} . \delta$-TaON is a metastable polymorph and about $20 \mathrm{~kJ} / \mathrm{mol}$ less stable than the thermodynamically stable $\beta$-polymorph [7]. No intermediate phase was observed during the experiments. It should be mentioned that thermoanalytical measurements (DTA/TG) were performed for all described compounds. No significant thermal effects (exo- or endothermic) or mass changes were observed in the relevant temperature regions.

A comparison of this work and formerly presented results might be difficult due to diversity and amount of side phases. Those problems were discussed above. The coordination polyhedra are now more conformable with experimental and theoretical data of the Mg-containing compound. A detailed study on physical properties, especially photocatalytic activity, might be difficult due the insufficient phase purity. A severe problem for neutron diffraction studies, important for the experimental determination of the anion distribution, is the small product yield $(\sim 10 \mathrm{mg})$ per reaction.

\section{Quantum-chemical calculations}

The calculated fundamental band gaps of the synthesized TaON $\beta-, \gamma$-, and $\delta$-polymorphs and the hypothetical rutile, fluorite and $\mathrm{t}-\mathrm{ZrO}_{2}$ polymorphs are summarized in Table 7 . For the $\delta$-polymorph the experimental structure parameters reported in this study were used. For all other polymorphs the lattice parameters optimized at DFT level in previous works were used. In all cases the smallest band gap energy corresponds to an indirect transition. 


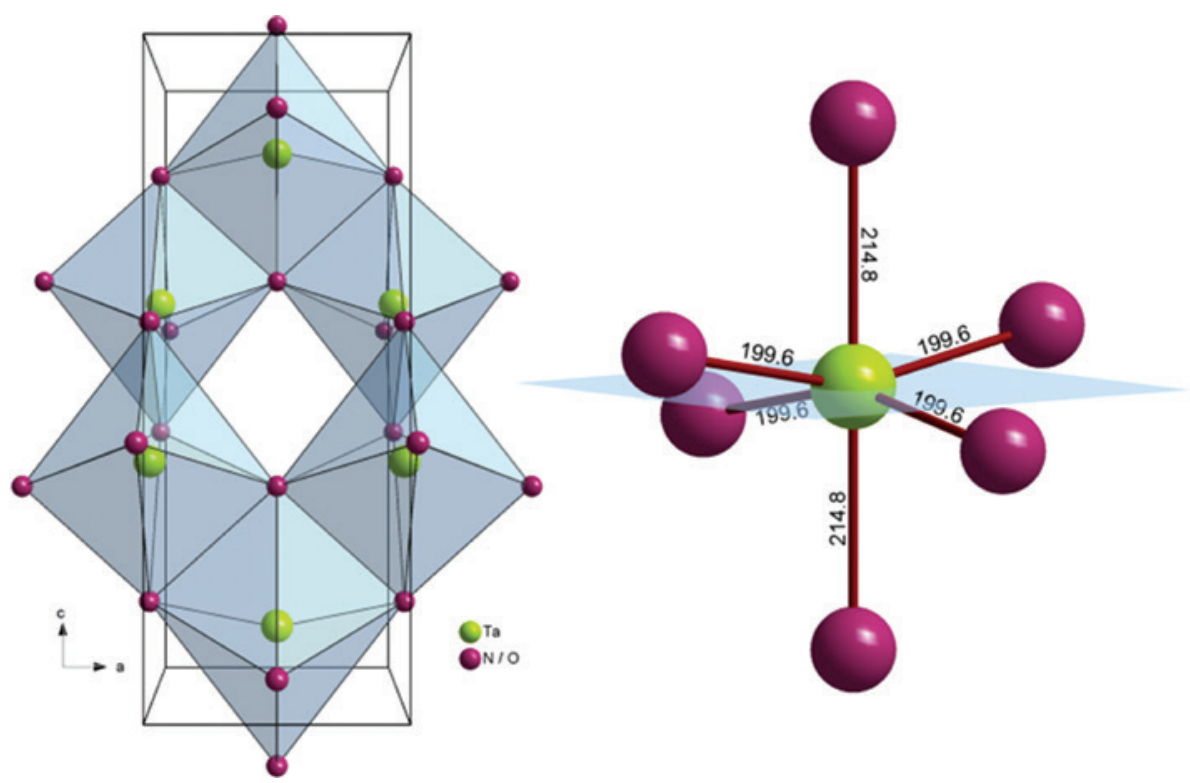

Fig. 11: Crystal structure of anatase-type TaON. Left: unit cell with coordination polyhedra. Right: Ta-O/N bond lengths. Bond lengths are presented in pm.

Tab. 7: Fundamental band gaps (eV) of TaON polymorphs calculated with the plasmon-pole approximation to GW implemented in GPAW.

\begin{tabular}{lrrr}
\hline Polymorph & This work & Previous studies & Exp. \\
\hline$\beta$-TaON & $2.99(3.20)$ & $3.2^{\mathrm{b}}$ & $2.4,2.8^{\mathrm{b}}$ \\
$\gamma$-TaON & $2.38(2.59)$ & $2.9^{\mathrm{c}}$ & $2.03(2.58)^{\mathrm{a}}$ \\
$\delta$-TaON & $2.52(3.01)$ & $2.85^{\mathrm{b}}, 3.2^{\mathrm{d}}$ & $1.73(2.06)^{\mathrm{a}} 2.4^{\mathrm{d}}$ \\
Rutile & $1.85(2.21)$ & $2.3^{\mathrm{b}}$ & \\
Fluorite & $1.78(2.50)$ & $2.46^{\mathrm{b}}$ & \\
t-ZrO2 & $1.57(1.77)$ & & \\
\hline
\end{tabular}

All calculated gaps obtained in this work correspond to indirect transitions. The corresponding direct gaps are given in parentheses. aptical band gaps, Ref. [51].

${ }^{b}$ Combined experimental and theoretical study using the hybrid functional PW1PW, Ref. [7].

'Theoretical study using the hybrid functional PW1PW, Ref. [6]. ${ }^{d}$ Combined experimental and theoretical study using the hybrid functional PBE0, Ref. [4].

Compared to the band gaps obtained in our previous hybrid DFT calculations, the GW gaps are systematically smaller, by $0.2-0.7 \mathrm{eV}$. Where comparison with experimental values is possible, this decrease corresponds to an improvement of the theoretical results. As a general trend, the band gaps decrease with decreasing stability of the polymorphs, in nice accord with the principle of maximum hardness [62]. It has to be noted that optical and fundamental band gaps differ by the exciton energy which is typically in the order of a few hundred meV for oxides. It is therefore not surprising that the calculated gaps are in all cases larger than the experimental values.
In order to correct for the excitonic effects, solution of the Bethe-Salpeter equations is necessary, which was beyond the scope of the present study. Based on the present results it can be concluded that the plasmon-pole GW approximation is useful as a computationally efficient screening method.

\section{Conclusion}

After the first publications on bixbyite-type $\mathrm{V}_{2} \mathrm{O}_{3}, \gamma$-TaON, and $\delta$-TaON powders we were able to improve the preparation conditions of all these metastable polymorphs. In the first two cases phase pure products were obtained and the yield of $\delta$-TaON was almost doubled to a phase purity of $82 \mathrm{wt} \%$. This clearly shows that new metastable polymorphs of simple compounds can be prepared by classical synthesis routes, pointing to additional new phases in the future. Moreover, metastable polymorphs may show structure function correlations distinctly different from those of the corresponding stable phases. These features will make them suitable model systems to advance our understanding of the properties and the design of improved functional materials. A first-principles quantum-chemical method was used to study the electronic structures of TaON polymorphs and their excitations. A semiquantitative agreement with measured optical spectra was obtained, so that it can be expected that this approach can be used for predictions of photocatalytic activity of solid compounds. 


\section{Experimental}

\section{X-ray diffraction}

A PANalytical X’Pert MPD Pro (Cu K $\mathrm{\alpha}_{\bar{\alpha}}$ radiation) and a Siemens D5000 ( $\mathrm{Cu} \mathrm{K} \mathrm{K}_{\alpha 1}$ radiation) powder diffractometer were used for XRD measurements at room temperature. Rietveld refinements including quantitative phase analyses were carried out using the program FULLPROF $2000[63,64]$. Profiles were fitted with a pseudo-Voigt function.

In situ XRD experiments were carried out in a $\theta-\theta$ scattering geometry on a STOE diffractometer equipped with a PAAR reaction chamber using $\mathrm{Cu} \mathrm{K} \alpha$ radiation $(40 \mathrm{kV}, 40 \mathrm{~mA})$. Isothermal experiments were performed from $613 \mathrm{~K}$ through $653 \mathrm{~K}$. Prior to isothermal measurements under reaction conditions the samples was heated to the corresponding temperature in helium $(25 \mathrm{~mL} / \mathrm{min})$. Subsequently, flow conditions were changed to $25 \mathrm{~mL} / \mathrm{min}$ propene (10 vol\% propene in helium) and $2.5 \mathrm{~mL} / \mathrm{min}$ oxygen. The gas-phase composition at the in situ cell outlet was analyzed online with a mass spectrometer (Pfeifer Omnistar). The $\mathrm{VO}_{2}(\mathrm{R})(110)$ main peak was measured between $26.6^{\circ}$ and $28.8^{\circ}(2 \theta)$ in steps of $0.012^{\circ}(2 \theta)$ and at a sampling time of $9 \mathrm{~s} / \mathrm{step}$. For a solid-state kinetic analysis, the program package WinXAS v3.2 [65] was used. Quantitative analysis of the phase composition was performed with the Rietveld program package FULLPROF $[63,64]$.

\section{X-ray absorption spectroscopy}

In situ transmission X-ray absorption spectroscopy (XAS) was measured at the V K edge (5.465 keV, Si(111), beam line C, measuring time $\sim 3.5 \mathrm{~min} / \mathrm{scan}$ ), at the Hamburg Synchrotron Radiation Laboratory, HASYLAB. In situ XAS measurements were performed in an in situ measuring cell. Samples were mixed with boron nitride (Alfa Aesar, $99.5 \%$ ) and pressed to a self-stabilized $5 \mathrm{~mm}$ diameter pallet [66]. The sample mass was calculated to obtain an edge jump of $\Delta \mu(d) \approx 0.4$ [66]. XAS data analysis was performed using the software WinXAS v3.2 [65].

\section{Elemental analyses}

The contents of nitrogen and oxygen were determined by hot gas extraction using a LECO TC-300/EF-300 N/O analyzer. $\mathrm{ZrO}_{2}$ and steel were used as standard materials. The accuracy is $\sim 2 \%$ of the N/O contents present. Hydrogen and carbon contents were measured using a Thermo Fisher Scientific Flash EA1112, which can also detect nitrogen and sulfur (CHNS-analysis).

\section{Quantum-chemical calculations}

The fundamental band gaps of TaON polymorphs were calculated with GPAW [8]. The Kohn-Sham wave functions were represented by real-space grids with converged grid size parameters $\mathrm{h}=0.12-0.15$. The Monkhorst-Pack grids were chosen as dense as possible within the limits of the computational resources. For example the irreducible Brillouin zone of $\gamma$-TaON was sampled with a $2 \times 6 \times 4$ grid.
PBE wavefunctions were used as basis for GW quasi-particle energy calculations. The plasmon-pole GW approximation was applied in order to reduce the computational effort. A cut-off energy of 400 $\mathrm{eV}$ was used which gave converged results for the band gaps within $0.05 \mathrm{eV}$. The number of bands was restricted to twice the number of occupied bands again due to limitations of computer resources. Test calculations for selected compounds showed only small changes $<0.1 \mathrm{eV}$ if the number of bands was further increased.

Acknowledgments: This work is supported by the German Science Foundation (DFG) within the priority program SPP 1415. XRF analysis by Dr. Rafael Zubrzycki (TU Berlin) and N/O-analysis by Brigitte Hahn and Steven Orthmann (TU Berlin) are gratefully acknowledged. The Hamburger Synchrotron Radiation Facility, HASYLAB, is acknowledged for providing beamtime. We thank Sigrid Imme and Barbara Dunker (TU Berlin) for CHNS-analysis.

\section{References}

[1] D. Weber, A. Stork, S. Nakhal, C. Wessel, C. Reimann, W. Hermes, A. Müller, T. Ressler, R. Pöttgen, T. Bredow, R. Dronskowski, M. Lerch, Inorg. Chem. 2011, 50, 6762.

[2] D. Weber, C. Wessel, C. Reimann, C. Schwickert, A. Müller, T. Ressler, R. Pöttgen, T. Bredow, R. Dronskowski, M. Lerch, Inorg. Chem. 2012, 51, 8524.

[3] H. Schilling, A. Stork, E. Irran, H. Wolff, T. Bredow, R. Dronskowski, M. Lerch, Angew. Chemie Int. Ed. 2007, 46, 2931.

[4] T. Lüdtke, A. Schmidt, C. Göbel, A. Fischer, N. Becker, C. Reimann, T. Bredow, R. Dronskowski, M. Lerch, Inorg. Chem. 2014, 53, 11691.

[5] D. A. Weber, Synthese und Charakterisierung neuer Oxide und Oxidnitride der Elemente der 5. und 6. Gruppe des Periodensystems, Technische Universität Berlin, Berlin, 2014.

[6] H. Wolff, T. Bredow, M. Lerch, H. Schilling, E. Irran, A. Stork, R. Dronskowski, J. Phys. Chem. A 2007, 111, 2745.

[7] T. Bredow, M.-W. Lumey, R. Dronskowski, H. Schilling, J. Pickardt, M. Lerch, Z. Anorg. Allg. Chem. 2006, 632, 1157.

[8] J. Paier, Catal. Letters 2016, 146, 861.

[9] E. J. Baerends, O. V. Gritsenko, R. van Meer, Phys. Chem. Chem. Phys. 2013, 15, 16408.

[10] A. Grüneis, G. Kresse, Y. Hinuma, F. Oba, Phys. Rev. Lett. 2014, 112, 096401.

[11] J. Enkovaara, C. Rostgaard, J. J. Mortensen, J. Chen, M. Dutak, L. Ferrighi, J. Gavnholt, C. Glinsvad, V. Haikola, H. A. Hansen, H. H. Kristoffersen, M. Kuisma, A. H. Larsen, L. Lehtovaara, M. Ljungberg, O. Lopez-Acevedo, P. G. Moses, J. Ojanen, T. Olsen, V. Petzold, N. A. Romero, J. Stausholm-Møller, M. Strange, G. A. Tritsaris, M. Vanin, M. Walter, B. Hammer, H. Häkkinen, G. K. H. Madsen, R. M. Nieminen, J. K. Nørskov, M. Puska, T. T. Rantala, J. Schiøtz, K. S. Thygesen, K. W. Jacobsen, J. Phys. Condens. Matter 2010, 22, 253202.

[12] C. Rostgaard, K. W. Jacobsen, K. S. Thygesen, Phys. Rev. B 2010, 81, 085103.

[13] F. Hüser, T. Olsen, K. S. Thygesen, Phys. Rev. B 2013, 87, 235132.

[14] J. Haber, Catal. Today 2009, 142, 100. 
[15] C. Hess, ChemPhysChem 2009, 10, 319.

[16] P. Liu, S.-H. Lee, H. M. Cheong, C. E. Tracy, J. R. Pitts, R. D. Smith, J. Electrochem. Soc. 2002, 149, H76.

[17] P. P. Prosini, Y. Xia, T. Fujieda, R. Vellone, M. Shikano, T. Sakai, Electrochim. Acta 2001, 46, 2623.

[18] J. Muster, G. T. Kim, V. Krstić, J. G. Park, Y. W. Park, S. Roth, M. Burghard, Adv. Mater. 2000, 12, 420.

[19] W. H. Zachariasen, Geol. Foereningan i Stock. Foerhandlingar 1929, 51, 123.

[20] N. F. Mott, Metal-insulator Transition, 1st ed. Taylor and Francis, London 1974.

[21] K. Held, G. Keller, V. Eyert, D. Vollhardt, V. I. Anisimov, Phys. Rev. Lett. 2001, 86, 5345.

[22] L. W. Finger, R. M. Hazen, J. Appl. Phys. 1980, 51, 5362.

[23] D. B. McWhan, J. P. Remeika, Phys. Rev. B 1970, 2, 3734.

[24] P. D. Dernier, M. Marezio, Phys. Rev. B 1970, 2, 3771.

[25] R. M. Moon, Phys. Rev. Lett. 1970, 25, 527.

[26] C. Wessel, C. Reimann, A. Müller, D. Weber, M. Lerch, T. Ressler, T. Bredow, R. Dronskowski, J. Comput. Chem. 2012, 33, 2102.

[27] A. Bergerud, R. Buonsanti, J. L. Jordan-Sweet, D. J. Milliron, Chem. Mater. 2013, 25, 3172.

[28] N. Sarmadian, R. Saniz, B. Partoens, D. Lamoen, J. Appl. Phys. 2015, 117, 015703.

[29] S. Nakhal, D. Weber, E. Irran, M. Lerch, B. Schwarz, H. Ehrenberg, Z. Krist. 2013, 228, 347.

[30] R. D. Shannon, C. T. Prewitt, Acta Crystallogr. Sect. B 1969, 25, 925.

[31] R. E. Rundle, N. C. Baenziger, A. S. Wilson, R. A. McDonald, J. Am. Chem. Soc. 1948, 70, 99.

[32] N. Masaki, H. Tagawa, J. Nucl. Mater. 1975, 57, 187.

[33] E. Füglein, R. Hock, M. Lerch, Z. Anorg. Allg. Chem. 1997, 623, 304.

[34] S. Nakhal, W. Hermes, T. Ressler, R. Pöttgen, M. Lerch, Z. Naturforsch. 2009, 64b, 281.

[35] C. Reimann, D. Weber, M. Lerch, T. Bredow, J. Phys. Chem. C 2013, 117, 20164.

[36] R. E. Carter, J. Chem. Phys. 1961, 34, 2010.

[37] A. M. Ginstling, B. I. Brounshtein, J. Appl. Chem. USSR 1950, 23, 1327.

[38] G. Brauer, J. R. Weidlein, Angew. Chemie Int. Ed. 1965, 4, 875.

[39] Y. A. Buslaev, M. A. Glushkova, M. M. Ershova, E. M. Shustorovich, Neorg. Mat. 1966, 2, 2120.

[40] Y. A. Buslaev, G. M. Safronov, V. I. Pakhomov, M. A. Glushkova, V. P. Repko, M. M. Ershova, A. N. Zhukov, T. A. Zhdanova, Neorg. Mat. 1969, 5, 45.

[41] M.-W. Lumey, R. Dronskowski, Z. Anorg. Allg. Chem. 2003, 629, 2173.
[42] M.-W. Lumey, R. Dronskowski, Z. Anorg. Allg. Chem. 2005, 631, 887.

[43] J. E. Lowther, Phys. Rev. B 2005, 72, 172105.

[44] K. Woodhead, S. Pascarelli, A. L. Hector, R. Briggs, N. Alderman, P. F. McMillan, Dalt. Trans. 2014, 43, 9647.

[45] Z. Wang, J. Hou, C. Yang, S. Jiao, K. Huang, H. Zhu, Energy Environ. Sci. 2013, 6, 2134.

[46] Q. Gao, N. Liu, S. Wang, Y. Tang, Nanoscale 2014, 6, 14106.

[47] T. Okubo, M. Kakihana, J. Alloys Compd. 1997, 256, 151.

[48] M. Lerch, J. Lerch, R. Hock, J. Wrba, J. Solid State Chem. 1997, 128, 282.

[49] M. Jansen, H. P. Letschert, Nature 2000, 404, 980.

[50] G. Hitoki, T. Takata, J. N. Kondo, M. Hara, H. Kobayashi, K. Domen, Chem. Commun. 2002, 2, 1698.

[51] S. Cosgun, Synthese und Charakterisierung Tantaloxidnitridbasierter Verbindungen für die photokatalytische Wasserspaltung, Technische Universität Berlin, Berlin, 2015.

[52] D. Armytage, B. E. F. Fender, Acta Crystallogr. Sect. B 1974 , 30, 809.

[53] A. F. Hollemann, N. Wiberg, E. Wiberg, Lehrbuch der Anorganischen Chemie, 102nd ed. De Gruyter, Berlin, Boston 2008.

[54] R. D. Shannon, Acta Crystallogr. Sect. A 1976, 32, 751-767.

[55] M. Harb, P. Sautet, E. Nurlaela, P. Raybaud, L. Cavallo, K. Domen, J.-M. Basset, K. Takanabe, Phys. Chem. Chem. Phys. 2014, 16, 20548.

[56] H. Schilling, M. Lerch, A. Börger, K.-D. Becker, H. Wolff, R. Dronskowski, T. Bredow, M. Tovar, C. Baehtz, J. Solid State Chem. 2006, 179, 2416.

[57] A. Stork, H. Schilling, C. Wessel, H. Wolff, A. Börger, C. Baehtz, K.-D. Becker, R. Dronskowski, M. Lerch, J. Solid State Chem. 2010, 183, 2051.

[58] A. Suzuki, Y. Hirose, D. Oka, S. Nakao, T. Fukumura, S. Ishii, K. Sasa, H. Matsuzaki, T. Hasegawa, Chem. Mater. 2014, 26, 976.

[59] A. Suzuki, Y. Hirose, D. Oka, S. Nakao, T. Fukumura, T. Hasegawa, Jpn. J. Appl. Phys. 2015, 54, 080303.

[60] H. Wolff, M. Lerch, H. Schilling, C. Bähtz, R. Dronskowski, J. Solid State Chem. 2008, 181, 2684.

[61] J. K. Burdett, T. Hughbanks, G. J. Miller, J. W. Richardson, J. V. Smith, J. Am. Chem. Soc. 1987, 109, 3639.

[62] R. G. Pearson, Chemical Hardness, 1st ed., Wiley-VCH, Weinheim, New York 1997.

[63] J. Rodríguez-Carvajal, in Abstr. Satell. Meet. Powder Diffr. XV IUCr Congr., 1990, 127.

[64] J. Rodríguez-Carvajal, Physica B 1993, 192, 55.

[65] T. Ressler, J. Synchrotron Radiat. 1998, 5, 118.

[66] T. Ressler, Anal. Bioanal. Chem. 2003, 376, 584. 